\title{
Formidable females and the power trajectories of socially integrated male vervet monkeys
}

\author{
Christopher Young ${ }^{\text {a, b, * }}$, Richard McFarland ${ }^{c}$, Louise Barrett ${ }^{\text {a, b }}$, S. Peter Henzi a, b \\ ${ }^{a}$ Department of Psychology, University of Lethbridge, Lethbridge, Canada \\ ${ }^{\mathrm{b}}$ Applied Behavioural Ecology and Ecosystems Research Unit, The University of South Africa Florida, South Africa \\ ${ }^{\mathrm{c}}$ Department of Anthropology, University of Wisconsin-Madison, Madison, WI, U.S.A.
}

\section{A R T I C L E I N F O}

\section{Article history:}

Received 29 June 2016

Initial acceptance 21 July 2016

Final acceptance 29 December 2016

Available online 20 February 2017

MS. number: 16-00575

\section{Keywords:}

aggression

dominance hierarchy

grooming

reproductive control

sexual conflict

social networks
Sexual conflict theory expects females to avoid nonoptimal mating attempts by males. Although female vervet monkeys, Chlorocebus pygerythrus, can resist direct mating attempts, higher-ranking males still have more mating opportunities than lower-ranking ones. We presume that rank-related access reflects male-male competition that may conflict with female reproductive objectives. We extend an earlier report of codominance in this species to show that powerful females can undermine the restrictions imposed through male-male competition by improving the dominance rank of preferred male associates. We found that the dominance hierarchies of the sexes were comprehensively interdigitated and that males who had more female spatial associates, and who groomed with well-connected females, were more likely improve their Elo-ratings, which we use as an index of male power. The effects of partner number and integration, which predicted the probability of the initiation of aggression by lowerranking males, suggest that association with females offered the prospect of protected threat if this likelihood increased. Although female rank and aggression were not directly consequential for males, we argue that female power and influence are intertwined and that both stem from the strength of female reproductive control.

( $) 2017$ Published by Elsevier Ltd on behalf of The Association for the Study of Animal Behaviour.
Reproductive conflict between the sexes can be characterized as resistance by one sex to attempts by the other to coerce them into matings that may not optimize offspring viability (Gowaty, 2004); that is, for one sex to undercut the other's choice of mates. Where competition between males selects for size and weaponry, and males are larger than females, male curtailment of female choice has two components: direct monopolization of females and the suppression of reproductive access by male rivals. These generally work in conjunction insofar as a male that can control female movement should also be able to control access to them (Andersson \& Simmons, 2006). However, even where females can, to a greater or lesser extent, evade immediate control by males, the ability of males to inhibit rivals, either directly, through interference (Wong \& Candolin, 2005), or indirectly, through 'psychological castration' (Creel, Dantzer, Goymann, \& Rubenstein, 2013; Henzi, 1981; Kraus, Heistermann, \& Kappeler, 1999), will still circumscribe the expression of female mate choice.

\footnotetext{
* Correspondence: C. Young, Department of Psychology, University of Lethbridge, 4401 University Drive, Lethbridge T1K 3M4, Canada.

E-mail address: christopher.young@uleth.ca (C. Young).
}

Female vervet monkeys, Chlorocebus pygerythrus, face the latter predicament. Although they are able successfully to resist mating attempts by males (Freeman, 2012; Keddy, 1986), higher-ranking males nevertheless mate more frequently than do lower-ranking ones (Freeman, 2012; Keddy, 1986; Struhsaker, 1967). This suggests either that females cannot prevent high-ranking males from mating, despite their ability to resist in some circumstances, or that they actively prefer higher-ranking males and are less likely to resist their mating attempts.

Female resistance to male mating attempts is facilitated by the intrinsic difficulties of sexual monopolization in an arboreal habitat (Henzi \& Lawes, 1987), but it may also occur because some females, despite being much smaller and with less impressive weaponry, appear to outrank some males (Struhsaker, 1967). To the extent that this observation of 'codominance' (Hemelrijk, Wantia, \& Isler, 2008) or hierarchical integration is generalizable, it also offers the possibility that some, if not all, females are in a position to intervene and influence the dominance rank of males to the females' benefit (Raleigh \& McGuire, 1989; see also Surbeck \& Hohmann, 2013, for bonobos, Pan paniscus). That is, if higher-ranking males can reduce the mating opportunities of subordinates independently of their attempts at monopolization, then a female who improves or helps 
sustain the rank of a favoured male will also improve her reproductive access to him. As this is clearly also in the interests of the assisted males, we might expect them to cooperate and to promote affiliation with females.

If females are codominant, then we might expect them to express their influence in two, nonmutually exclusive, ways. First, they may aggressively target particular, nonpreferred males. In many other taxa, recipients of repeated aggression have higher physiological stress levels (Creel et al., 2013), and are susceptible to the rank loss associated with 'winner-loser' effects (Chase, Tovey, SpanglerMartin, \& Manfredonia, 2002; Franz \& Alberts, 2015; Silk, 2002). Second, females might provide agonistic support for preferred males. They could do so directly, by intervening in male-male aggression as males do (Young, Majolo, Schülke, \& Ostner, 2014), or indirectly, where the mere possibility of support prevents the escalation of a contest and increases a male's extrinsic power (Berghänel, Ostner, \& Schülke, 2011; Surbeck \& Hohmann, 2013; Surbeck, Mundry, \& Hohmann, 2011; Wittig et al., 2007) allowing them to win dyadic encounters with higher-ranking opponents. Importantly, of course, this coincides with the interests of most males, aligning the reproductive strategies of the sexes more closely and making social integration valuable to both parties. It follows, therefore, that, to the extent to which it increases the probability of effective support, social integration should be beneficial to males.

Here, after demonstrating extensive female codominance in our population, we use estimates of male power trajectories, derived from Elo-ratings (Albers \& de Vries, 2001; Neumann et al., 2011), across successive 6-month blocks centred on the mating and birth seasons, and social network (SN) estimates of male-female affiliation to assess the following predictions. (1) Females exert a direct influence on male power trajectories by targeting males aggressively, with males who receive more frequent aggression from females being more likely to have a negative power trajectory. (2) The stronger a male's integration into the female network, the more frequently he will (i) receive agonistic support from them, (ii) initiate aggression against higher ranked opponents and (iii) win dyadic agonistic encounters up the hierarchy, (iv) leading to positive power trajectories.

\section{METHODS}

\section{Study Site and Subjects}

Data were collected between March 2012 and September 2015 at the Samara Private Game Reserve, South Africa $\left(32^{\circ} 22^{\prime} \mathrm{S}\right.$, $24^{\circ} 52^{\prime} \mathrm{E}$ ), on three groups (PT, RBM, RST) of wild, fully habituated and individually recognizable vervet monkeys occupying semiarid riverine woodland (Pasternak et al., 2013). Group composition varied across the three groups and the study period ( $N_{\mathrm{RBM}}$ Males: 7-17; $N_{\text {RBM Females: }}$ 10-14; $N_{\text {RST Males }}$ : 10-15; $N_{\text {RST Females: }}$ 17-18; $N_{\text {PT Males: }}$ 4-10; $N_{\text {PT Females: }} 8-11$ ). Each group was followed for $10 \mathrm{~h}$ per day. In winter, daylight hours (0730-1730) coincided with our $10 \mathrm{~h}$ sampling period. During the longer daylight period in summer, we balanced our daily follows so there were equal numbers of days that began at dawn (0400 hours) and finished $10 \mathrm{~h}$ later in midafternoon, and days that terminated at 1900 hours and began $10 \mathrm{~h}$ earlier in the mid-morning.

\section{Behavioural Data Collection}

We used scan sampling (Altmann, 1974) at 30 min intervals to record the general activity (resting, moving, foraging or allogrooming) of each adult group member and the identities of all its neighbours within a $2 \mathrm{~m}$ radius, across each study day. Each scanning period lasted a maximum of $10 \mathrm{~min}$ to ensure as many animals as possible were sampled (i.e. to permit researchers to identify animals beyond the researchers' immediate vicinity), and most individuals were recorded in each scan $\left(N_{\text {total }}=290019\right.$ scans. The mean number of scans/animal/6-month block $( \pm \mathrm{SD})$ were: $\mathrm{RST}_{\text {Males }}=305.10 \pm 220.54 ; \mathrm{RST}_{\mathrm{Females}}=351.94 \pm 274.71 ; \mathrm{RBM}_{\text {Males }}$ $=379.22 \pm 224.25 ; \quad R_{\text {BMemales }}=479.43 \pm 309.58 ; \quad \mathrm{PT}_{\text {Males }}=418$. $\left.66 \pm 255.41 ; \mathrm{PT}_{\mathrm{Females}}=580.18 \pm 399.06\right)$. Additionally, for records of allogrooming, we recorded both the identity of the partner and the direction of grooming. Agonistic behaviours, the identities of participants and the outcomes were recorded ad libitum. While we certainly did not see all agonistic encounters, we have no reason to suspect any systematic bias in the sampling.

\section{Dominance Rankings}

We divided the 42-month study period into seven consecutive 6-month blocks centred on either the mating (March-August) or the birth (September-February) season. Data from ongoing, ad libitum observations of decided dyadic agonism ( $N_{\text {Male-Male }}$ $\left.=2486 ; \quad N_{\text {Male-Female }}=1219 ; \quad N_{\text {Female-Female }}=4040\right)$ were then used to construct both sex-specific and intersexual (hereafter 'integrated') dominance hierarchies for all adults in each 6-month period. This allowed us to estimate the proportion of group members of the opposite sex that each individual outranked. To do so, we determined the number of individuals of the opposite sex that ranked below the target individual and divided this by the total number of individuals of the opposite sex in that 6-month period/ group.

For each troop, in each time period, dominance rank was expressed as a standardized normalized David's score, using the $\mathrm{R}$ package 'DomiCalc' (Schmid \& de Vries 2013) in R 3.2.2 (The R Foundation for Statistical Computing, Vienna, Austria, http://www. r-project.org). Standardization enables direct comparison across groups of different size (Henzi, Forshaw, Boner, Barrett, \& Lusseau, 2013). Using decided dyadic agonism, we determined the level of aggression each male received from females over each 6-month block. As our study site is situated in open, semiarid riverine woodland with generally high visibility, we are confident we missed very few agonistic interactions and that there was no systematic bias in the likelihood of detecting encounters. We also controlled for observer effort (number of observers per group per scan day; range 1-3) and for the presence of each individual animal in the group on each scan day (based on daily group census of an individual animal's presence/absence within the group). We used the R package 'steepness' (Leiva \& De Vries, 2011) to estimate the slopes of dominance hierarchies and 'Domicalc' to determine directional consistency and $h$ ' as an estimate of linearity (Table 1 ).

\section{Male Power Trajectories}

To determine changes in male power over time (hereafter power trajectories), we estimated each male's power trajectory across each 6-month block by determining Elo-ratings (Albers \& de Vries, 2001; Neumann et al., 2011), using the R package 'EloRating' (Neumann \& Kulik, 2014). A male's Elo-rating is described by a value that increases or decreases depending on the outcome of contests between rated males. After each aggressive interaction, the winner takes points from the loser, with the difference in the current ratings of the loser and winner dictating the number of points that are gained or lost. For example, in a contest between a high-rated winner and low-rated loser, only a few points will be transferred as the winner began with a high probability of winning (reflected in their higher rating), whereas if the low-rated individual wins, a larger number of points are transferred to reflect the lower probability that this would occur. The number of points that can be won or lost is 
Table 1

Summary measures (mean $\pm \mathrm{SD}$ ) for estimates of the intra- and intersex dominance hierarchies for each of the three study groups across the six blocks comprising the study period

\begin{tabular}{lllll}
\hline Group & $\begin{array}{l}\text { Dominance } \\
\text { hierarchy }\end{array}$ & Steepness & $\begin{array}{l}\text { Directional } \\
\text { consistency }\end{array}$ & Linearity $\left(h^{\prime}\right)$ \\
\hline PT & Male-Male & $0.429 \pm 0.200$ & $0.831 \pm 0.102$ & $0.666 \pm 0.200$ \\
& Male-Female & $0.247 \pm 0.190$ & $0.861 \pm 0.080$ & $0.343 \pm 0.190$ \\
& Female-Female & $0.430 \pm 0.180$ & $0.928 \pm 0.065$ & $0.666 \pm 0.196$ \\
RBM & Male-Male & $0.190 \pm 0.138$ & $0.784 \pm 0.092$ & $0.372 \pm 0.178$ \\
& Male-Female & $0.060 \pm 0.044$ & $0.778 \pm 0.327$ & $0.150 \pm 0.044$ \\
& Female-Female & $0.351 \pm 0.223$ & $0.949 \pm 0.055$ & $0.614 \pm 0.224$ \\
RST & Male-Male & $0.140 \pm 0.142$ & $0.838 \pm 0.151$ & $0.322 \pm 0.127$ \\
& Male-Female & $0.110 \pm 0.120$ & $0.902 \pm 0.092$ & $0.190 \pm 0.100$ \\
& Female-Female & $0.200 \pm 0.208$ & $0.981 \pm 0.021$ & $0.390 \pm 0.227$ \\
\hline
\end{tabular}

determined by the $k$ value, which we set to the recommended level of 100 (Neumann et al., 2011). To provide a stable baseline for the Elo-ratings, we used the 6-month period prior to the beginning of analyses, i.e. between September 2011 and February 2012, to generate each male's initial rating. A male's Elo scores at the start and end of each 6-month period thus described his power trajectory, expressed as the slope of the line connecting them. Positive and negative slopes indicate increasing and decreasing power within the group, respectively, while the magnitude of the slope identifies the rate of increase or decrease. 'Power' better reflects the Elo estimates than does 'rank', which we use to refer to the comparatively stable position of a male in the dominance hierarchy; Elo-ratings indicate shifts in competitive ability that do not necessarily indicate changes in relative rank positions.

\section{Male-Female Associations}

We described male-female social relationships by constructing spatial $(<2 \mathrm{~m})$ and grooming association matrices for each 6 -month block. In doing so, we controlled for both the number of weeks each male was in each group and for observation effort by dividing each dyadic association score by the total number of scans in which each dyad member was observed. We used the function 'subgraph.edges' in the R package 'igraph' (Csardi \& Nepusz, 2006) to examine each male's association patterns with all females in the group and derive two measures of association in the social network (SN). We used eigenvector centrality (EC), which estimates a male's centrality as a function of his partner's centrality, to estimate the extent of integration, and degree to account for the number of females to which a male is connected, and which has been shown to be an important predictor of performance in our population (Josephs, Bonnell, Dostie, Barrett, \& Henzi, 2016; McFarland et al., 2015). We also included a dyadic measure of male-female association. To do so, we determined the top female partner of each male for each time period and included the intrasexual standardized female rank as a measure of the resource-holding potential of a male's top female ally. We considered grooming and proximity association separately, as each targets different network properties (Castles et al., 2014), generating four SN measures.

\section{Statistical Analysis}

To assess our hypotheses, we constructed a series of linear and generalized mixed models. To identify the drivers of position in the integrated dominance hierarchy, we entered the proportion of the opposite sex outranked as the response variable, standardized rank (StdRank, calculated from the intrasexual dominance hierarchy), sex and the proportion of males in the group (Hemelrijk et al., 2008), as predictor variables, specifying an interaction between StdRank and sex (model 1).
To investigate the influence of male-female social dynamics on male power trajectories, we constructed three models. We used a linear mixed model (LMM) to assess the effects of the rate of aggression received from females (number of aggressive bouts summed for each 6-month period, controlling for observation effort as per Freeman, Young, Barrett, \& Henzi, 2016), the combined rank of each male's female associates (the sum of the StdRank of all associated females), the number of males and the four SN measures on the magnitude of change in the trajectory, where positive and negative values indicate direction of change (model 2). We excluded male rank from consideration here because of the lack of independence between current rank and the possibility of past female assistance.

To determine whether integration into the female network provides males with the benefit of increased extrinsic power, we ran two further generalized linear mixed models (GLMMs: binomial family and logit-link function) that addressed zero inflation in the response variables (Papke \& Wooldridge, 1993). We weighted the response variables by sample size and entered male number, male StdRank, summed female StdRank, top female partner and the SN measures as predictors.

First, after excluding alpha males, we examined how frequently a male initiated aggression against higher ranked males. To do so, we entered the proportion of aggression initiated against higherranked individuals relative to all agonistic contests in which each male was involved as the response variable (model 3). Then we examined the frequency of agonistic support from females, where our response variable was the proportion of agonistic contests, relative to all his agonistic encounters, in which a male received female support (model 4). Here we restricted the analysis to the last three periods, for which appropriately detailed coalition data were available.

Finally, using the data from the last three periods, which necessitates a modified model 2, we asked whether a male's rank trajectory was influenced by the frequency of agonistic support he received from females (entered as a proportion of all his agonistic encounters) and the summed rank of his female associates (model 5).

We ran the analyses in R, using in the 'Ime4' package (Bates, Maechler, Bolker, \& Walker, 2015) to model outcomes and the 'MuMIn' package (Barton \& Barton, 2015) to generate marginal and conditional $R^{2}$ values for the fixed effects and whole models, respectively (Nakagawa \& Schielzeth, 2012). We controlled for repeated measures by entering subject identity (ID) and time period as crossed random effects (models 1, 2 and 5). In models 3 and 4, we omitted time period and, to address model overdispersion, specified observation level as a crossed random effect (Harrison, 2015). Prior to running each model, we assessed collinearity among predictor variables by calculating variance inflation factors after regression, setting a boundary of 4 (Pan \& Jackson, 2008). Although we were able to generate weighted (i.e. directional) grooming network measures from our data, the high degree of collinearity between weighted grooming social network measures (variance inflation factors, VIFs ca. 9) precluded analyses based on directionality, although the high collinearity is informative in and of itself. No other VIFs exceeded 3.5. We applied a cube root transform to the proportion of female coalitionary support in model 5, to improve the fit to normality.

Given the number of explanatory variables in relation to our sample sizes, we first ran models with the identified explanatory variables and group identity as a control variable. We then used likelihood ratio tests to determine whether group identity improved model fit. Models that included group identity either performed worse or the same as those without it and so we excluded it from the final analyses. As neither model 3 nor model 4 converged with the prespecified variables, we used the 'MuMIn' 

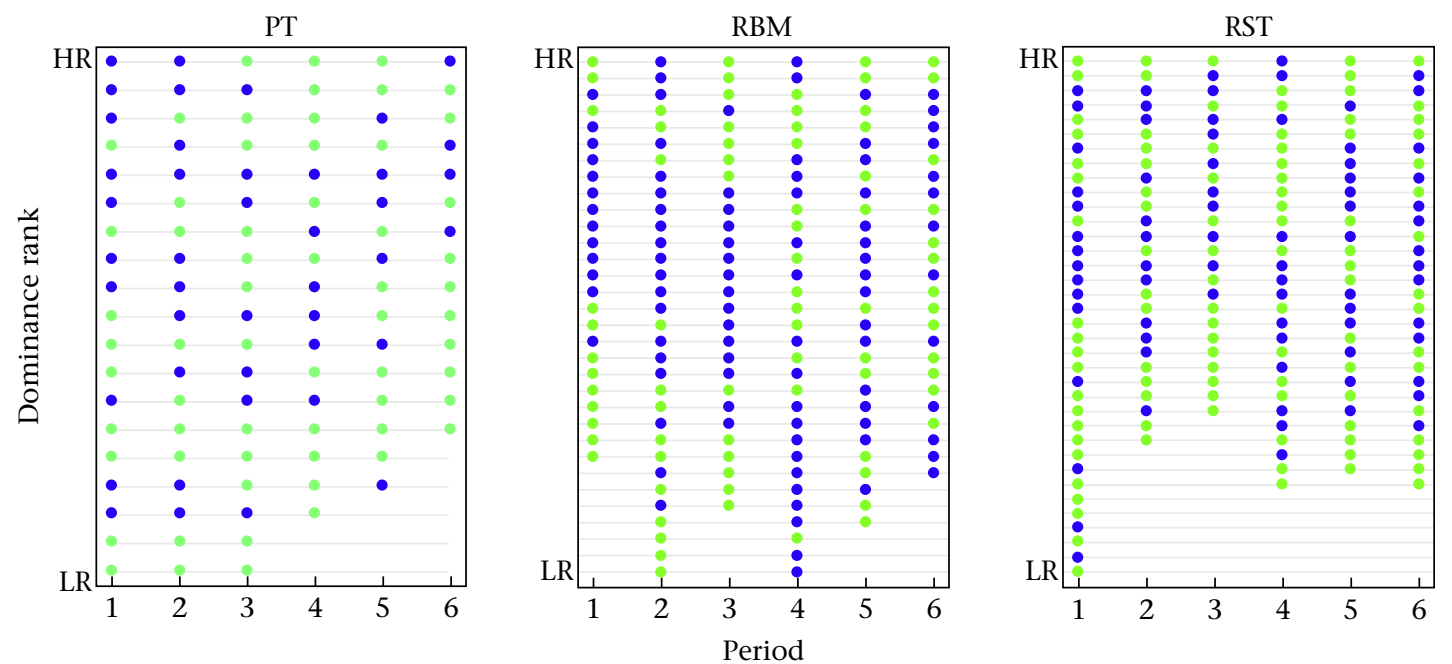

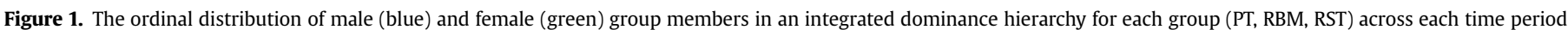
HR: high-ranking; LR: low-ranking.

package to extract the subsets of reduced models that did converge. We then compared the relative performance of these candidate models, using the Akaike information criterion corrected for sample size (AICC). Models within $\triangle \mathrm{AICc} \leq 5$ of the best model were then used to derive averaged model outcomes (Burnham, Anderson, \& Huyvaert, 2011).

We evaluated the distributions of the response variables and the residuals of all models, and, where appropriate, compared obtained standard errors to robust standard errors (King \& Roberts, 2015). Tests were two-tailed. We follow Colquhoun (2014) in describing outcomes as indicating weak $(P \sim 0.05)$, moderate $(P \sim 0.01)$ or strong $(P \sim 0.001)$ evidence for effects.

\section{Ethical Note}

All protocols were noninvasive and adhered to the laws and guidelines of South Africa and Canada. Procedures were approved by the University of Lethbridge Animal Welfare Committee (Protocols 0702 and 1505).

\section{RESULTS}

\section{Codominance}

Females won 580 (47.58\%) of the 1219 dyadic contests with males. For both sexes, the proportion of the other sex outranked ranged from 0 to 1 (Fig. 1, Table 1). Across the 6-month time blocks, standardized within-sex rank had a strong positive influence on the proportion of individuals of the opposite sex that were outranked. Females outranked a greater proportion of the opposite sex than did males, but the influence of rank on the proportion of the other sex dominated was stronger for males. The proportion of males in each group had no effect (model 1, Table 2).

\section{Male Power Trajectories}

The slopes of male power trajectories ranged from -11.00 to 5.7 (mean $=-0.09 \pm 1.91 \mathrm{SD}$ ). Male rank trajectories were influenced by neither the extent of aggression received from females nor the summed ranks of female associates. There was weak evidence that proximity degree, and strong evidence that grooming EC, were
Table 2

Results from the LMM to assess the fixed effects of the proportion of males in the group, sex, standardized within-sex dominance rank and their interaction on the proportion of the opposite sex dominated (model 1)

\begin{tabular}{lllllll}
\hline Parameter & $\beta$ & SE & z & $P$ & $95 \%$ CI & \\
\hline Proportion males & -0.147 & 0.176 & -0.840 & 0.402 & -0.492 & 0.198 \\
Sex (Ref: Females) & -0.088 & 0.031 & -2.790 & 0.005 & -0.149 & -0.026 \\
StdRank & 0.207 & 0.034 & 6.150 & $<0.001$ & 0.141 & 0.273 \\
$\begin{array}{l}\text { Sex*StdRank } \\
\quad \text { Ref: Female) }\end{array}$ & 0.218 & 0.053 & 4.150 & $<0.001$ & 0.115 & 0.321 \\
$\quad$ & & & & & \\
Intercept & 0.611 & 0.088 & 6.970 & $<0.001$ & 0.439 & 0.783 \\
\hline
\end{tabular}

Whole model: $\log$ likelihood $=-21.118, \mathrm{X}_{4}^{2}=2141.21, P<0001, N=425 . R_{\text {MAR }}^{2}$ GINAL $=0.395 ; R^{2}$ CONDITIONAL $=0.793$. Animal identity and time period were entered as crossed random effects to control for repeated measures. CI: confidence interval; StdRank: sex-specific standardized rank.

associated with a positive power trajectory (model 2 , Table 3 , Fig. 2).

\section{Agonistic Contests up the Hierarchy}

There was moderate evidence for the positive effects of summed female rank and both proximity and grooming degree on the probability that a male would initiate aggressive encounters with higher-ranking males (model 3, Table 4).

Table 3

Results from the LMM to assess the fixed effects of the number of males, female aggression, summed female rank, top ranked female and four social network (SN) measures on a male's power trajectory (model 2)

\begin{tabular}{lllllll}
\hline Parameter & $\beta$ & SE & $\mathrm{z}$ & $P$ & $95 \% \mathrm{CI}$ & \\
\hline Male number & 0.002 & 0.045 & 0.050 & 0.960 & -0.086 & 0.090 \\
Summed & -0.293 & 0.266 & -1.100 & 0.271 & -0.815 & 0.228 \\
$\quad$ female rank & & & & & & \\
Female aggression & -85.324 & 143.072 & -0.600 & 0.551 & -365.740 & 195.092 \\
Top female partner & 0.203 & 0.210 & 0.970 & 0.332 & -0.208 & 0.615 \\
Proximity degree & 0.104 & 0.051 & 2.060 & 0.040 & 0.005 & 0.204 \\
Proximity EC & -0.034 & 0.913 & -0.040 & 0.970 & -1.824 & 1.756 \\
Grooming degree & -0.047 & 0.037 & -1.270 & 0.205 & -0.121 & 0.026 \\
Grooming EC & 3.224 & 1.144 & 2.820 & 0.005 & 0.983 & 5.466 \\
Intercept & -1.581 & 0.610 & -2.590 & 0.009 & -2.776 & -0.386 \\
\hline
\end{tabular}

Whole model: $\log$ likelihood $=-374.915, \mathrm{X}_{8}^{2}=23.55, P=0.003, N=189 . R^{2}{ }_{\text {MAR }}$ GINAL $=0.110 ; R^{2}$ CONDITIONAL $=0.759$. Animal identity, nested in time period, was entered as a random effect to control for repeated measures. CI: confidence interval; EC: eigenvector centrality. 

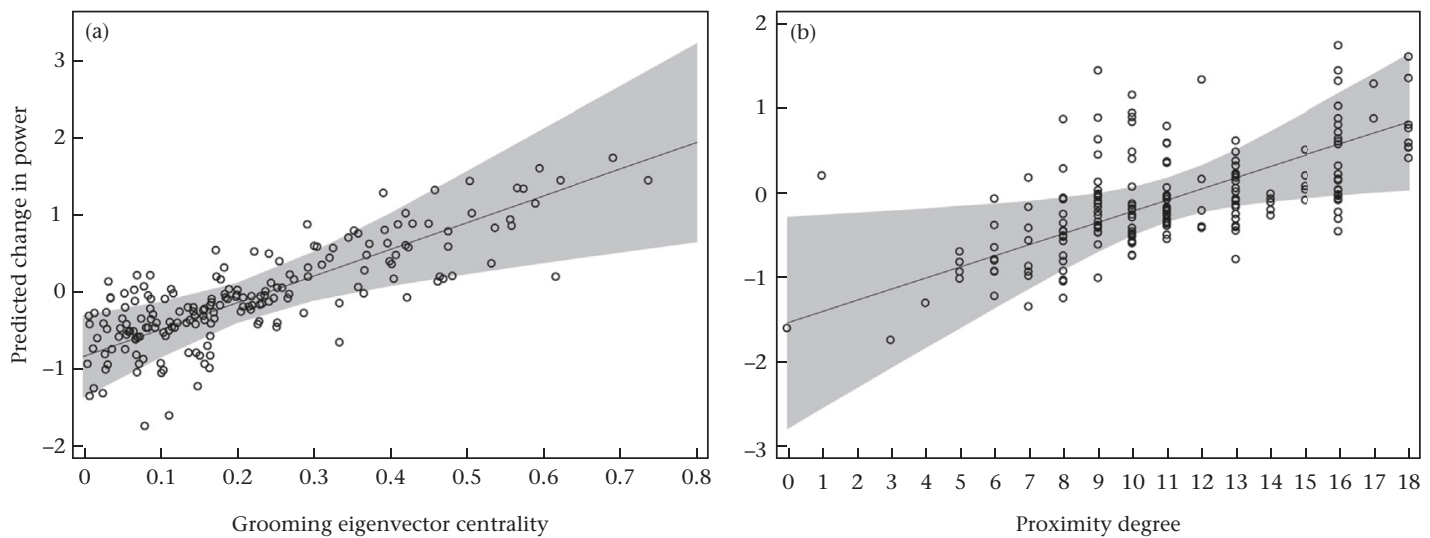

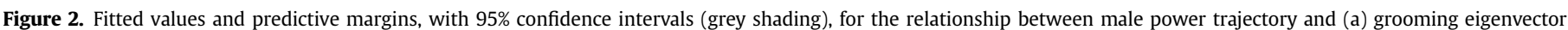
centrality and (b) proximity degree.

Table 4

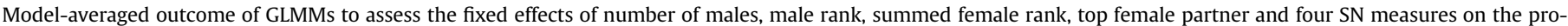
portion of a male's aggressive interactions that were directed up the hierarchy (model $3, N=171$ )

\begin{tabular}{|c|c|c|c|c|c|c|c|c|}
\hline Parameter & $\beta$ & SE & Adj. SE & $\mathrm{z}$ & $P$ & $95 \% \mathrm{CI}$ & & Importance \\
\hline Male number & 0.033 & 0.052 & 0.052 & 0.638 & 0.523 & -0.069 & -0.136 & 0.24 \\
\hline StdRank & -0.304 & 0.276 & 0.278 & 1.094 & 0.274 & -0.849 & -0.241 & 0.33 \\
\hline Summed female rank & 0.659 & 0.287 & 0.289 & 2.278 & 0.023 & -0.092 & -1.225 & 0.96 \\
\hline Proximity degree & 0.097 & 0.043 & 0.044 & 2.212 & 0.027 & -0.011 & -0.183 & 0.89 \\
\hline Proximity EC & 1.066 & 0.942 & 0.949 & 1.124 & 0.261 & -0.793 & -2.925 & 0.35 \\
\hline Grooming degree & 0.076 & 0.035 & 0.036 & 2.122 & 0.034 & -0.006 & -0.146 & 0.92 \\
\hline Grooming EC & -2.387 & 1.246 & 1.254 & 1.903 & 0.057 & -4.845 & -0.071 & 0.77 \\
\hline Top female partner & -0.005 & 0.205 & 0.206 & 0.026 & 0.979 & -0.409 & -0.398 & 0.17 \\
\hline Intercept & -3.878 & 0.498 & 0.502 & 7.733 & $<0.001$ & -4.861 & -2.895 & \\
\hline
\end{tabular}

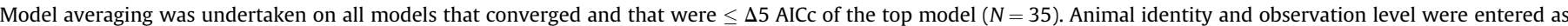

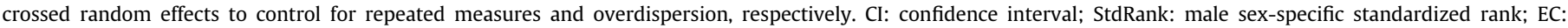
eigenvector centrality; importance: relative importance of the variable for the averaged model.

\section{Female Agonistic Support}

Males received agonistic support from females in 3.7\% of their agonistic encounters with other males. There was weak and strong evidence, respectively, for the positive effects of summed female rank and proximity EC on female coalitionary support but strong evidence for a negative association with proximity degree (model 4 , Table 5). There was, however, no evidence that coalitionary support from females was associated with male power trajectories (model 5, Table 6).

\section{DISCUSSION}

Our results indicate that the ranks of wild male and female vervets are comprehensively interdigitated, with one or more females in each group outranking all group males in at least three of the six periods, despite a substantial male bias in body mass (males: ca. $5.5 \mathrm{~kg}$; females: ca. $3.3 \mathrm{~kg}$; Pasternak et al., 2013). As this was not merely a consequence of the proportion of males in a group, a possibility suggested by comparative analysis (Hemelrijk et al., 2008), it confirms that female vervets have real power and hence the potential to be useful allies for males in aggressive competition. Nevertheless, there was no evidence that male power trajectories were influenced by females either targeting unfavoured males aggressively or by engaging in coalition formation with preferred males. Here, we note that the results of model 4 indicate contradictory effects for proximity and grooming degree on the likelihood of female participation in male-male aggression, for which we can offer no principled explanation. However, the low representation of male-female coalitions in male aggression and the absence of any

Table 5

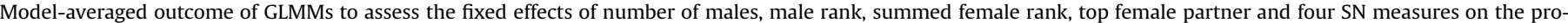
portion of a male's agonistic encounters with coalitionary support from females (model $4, N=98$ )

\begin{tabular}{|c|c|c|c|c|c|c|c|c|}
\hline & $\beta$ & SE & Adjusted SE & $\mathrm{z}$ & $P$ & $95 \% \mathrm{CI}$ & & Importance \\
\hline Male number & 0.048 & 0.089 & 0.090 & 0.529 & 0.597 & -0.129 & -0.224 & 0.230 \\
\hline StdRank & 0.150 & 0.409 & 0.414 & 0.362 & 0.718 & -0.661 & -0.961 & 0.200 \\
\hline Summed female rank & 1.206 & 0.591 & 0.598 & 2.015 & 0.044 & -0.033 & -2.379 & 0.800 \\
\hline Proximity degree & -0.198 & 0.074 & 0.075 & 2.628 & 0.009 & -0.345 & -0.050 & 0.990 \\
\hline Proximity EC & 4.170 & 1.535 & 1.551 & 2.689 & 0.007 & -1.131 & -7.210 & 0.920 \\
\hline Grooming degree & -0.005 & 0.043 & 0.044 & 0.117 & 0.907 & -0.091 & -0.081 & 0.190 \\
\hline Grooming EC & 2.569 & 1.700 & 1.718 & 1.496 & 0.135 & -0.797 & -5.936 & 0.500 \\
\hline Top female partner & -0.031 & 0.313 & 0.317 & 0.098 & 0.922 & -0.652 & -0.590 & 0.180 \\
\hline Intercept & -3.185 & 0.862 & 0.872 & 3.652 & $<0.001$ & -4.894 & -1.476 & \\
\hline
\end{tabular}

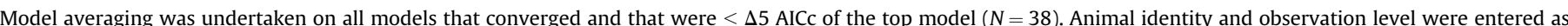

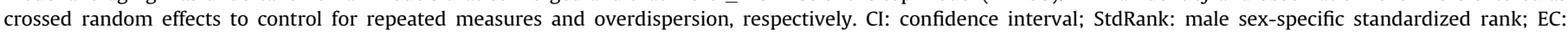
eigenvector centrality; importance: relative importance of the variable for the averaged model. 
Table 6

Results from the LMM to test the fixed effects of female agonistic support and the summed rank of female associates on male rank trajectory (model 5)

\begin{tabular}{|c|c|c|c|c|c|c|}
\hline Parameter & $\beta$ & SE & $\mathrm{z}$ & $P$ & $95 \% \mathrm{CI}$ & \\
\hline Summed female rank & 0.017 & 0.368 & 0.050 & 0.964 & -0.705 & 0.738 \\
\hline $\begin{array}{l}\text { Female coalitionary } \\
\text { support }\end{array}$ & -0.387 & 0.573 & -0.680 & 0.499 & -1.510 & 0.736 \\
\hline Intercept & 0.018 & 0.209 & 0.090 & 0.932 & -0.391 & 0.427 \\
\hline
\end{tabular}

Whole model: $\log$ likelihood $=-161.586 . \mathrm{X}_{2}^{2}=0.47, P=0.792, N=95 . R^{2}$ MARGIN$\mathrm{AL}=0.024 ; R^{2}$ CONDITIONAL $=0.024$. Animal identity and time period were entered as crossed random effects to control for repeated measures. CI: confidence interval.

contribution by coalitions to power trajectories suggest that this outcome may not be biologically relevant, although once we accrue a larger data set, we will assess more fully the dynamics of participation.

There was, on the other hand, good evidence that an improvement in power was associated with the extent to which males sustained grooming associations with well-connected females and, to a lesser extent, by spatial association with a larger number of females. The very high VIF values for our weighted social network estimates, indicating strong correlation between grooming given and grooming received, provide reason to believe that males contribute actively to this outcome. It is important to emphasize that we cannot consider the obvious relative importance of male efforts to increase power on their own behalf, especially through their independent interactions with other males. For this, we need more data and a different modelling approach. Instead, we demonstrate only that males benefit from association with females in ways that link to reproductive opportunities (see Freeman et al., 2016).

This caveat aside, our results indicate that the overt expression of female power, while real, is largely irrelevant in the context of male power trajectories. In other words, although females can and do dominate males, neither direct female aggression against unfavoured males nor coalitionary support for preferred males appear to influence male power trajectories. Nevertheless, they are clearly still influential in male careers. In our view, this is a puzzle that can be resolved by appreciating that female rank and social influence may originate from the same source: namely, the ability of females to regulate mating access by males (Freeman, 2012; Keddy, 1986), not least because such action is not undermined by male coalitions (Freeman et al., 2016), as it is for some baboons (Henzi \& Barrett, 2003). That is, because vervet females can resist male mating attempts, males may be inhibited from directing aggression towards females, in ways that would enhance male dominance, because such behaviour would increase female resistance, and result in a failure to gain mating access. By extension, such males may also be reluctant to attack males that are well integrated into female networks, especially where this integration connects males to higher-ranking females, because this similarly harms their own chances of forging relationships with these females and/or mating with them in the future.

It is precisely the ability of females to retaliate against males, therefore, that can explain why males with higher female grooming and proximity degree scores are more likely to initiate aggression up the hierarchy. That is, under circumstances when aggression is probable, those males that are connected to a larger number of female associates, who are likely to be in close proximity, are in a position to issue a protected threat (Kummer, 1967) against higherranking males, and so are more likely to initiate aggression. The fact that active female support is rare suggests that well-integrated males do not need such intervention, and therefore that integration in the female social network serves as a general inhibitor of aggression by rivals (see also Berghänel et al., 2011). There is preliminary support for this in vervets from a small captive study
(Raleigh \& McGuire, 1989) in which, after the removal of the alpha male, it was not the beta male, but the male with the strongest female ties, who became alpha despite an absence of active female intervention.

Further exploration of this idea requires both more detailed investigation of the dynamics of male interactions and comparative assessment in other species where females are smaller than males, where there is evidence of codominance, where male rank improves with tenure length and where females can exercise choice (in primates: inter alia: Soltis et al., 1997; Hemelrijk et al., 2008). The value of doing so lies in the balance it brings to the investigation of the benefits associated with affiliative heterosexual social relationships. Much of this work has focused on species where males outrank most, if not all, females in their groups, and so deals in the main with the potential benefits to females of associating with males (Archie, Tung, Clark, Altmann, \& Alberts, 2014; Nguyen, Horn, Alberts, \& Altmann, 2009). In some species, on the other hand, there is evidence that males may benefit from association with females (Ostner, Vigilant, Bhagavatula, Franz, \& Schülle, 2013; Soltis et al., 1997). As we argue for our vervets, this is tied to reproductive opportunities and may benefit lower ranking males disproportionately.

If it were purely a matter of female reproductive control inhibiting male attack or retaliation, with males deferring to females, rather than females actively winning contests against males, then we would expect females to rank above all males, which is not the case. Together with the fact that the position of females in the integrated hierarchy maps onto their rank in the female hierarchy, and that the aggregate rank of female associates is beneficial to males, this suggests that female dominance is somehow relevant to males in and of itself, and that males adjust their interactions with them accordingly. It is easy to appreciate that, given rank-related mating access (Freeman et al., 2016), lower-ranking males should antagonize fewer, if any, females, not only to improve mating opportunities in the short term (Henzi, 1982), but also to benefit from rank improvement over time. It also seems likely that, although high-ranking males will have profited, at least in part, from their earlier association with females, their relative priority of access lessens their need for continued female cooperation.

While this is a plausible explanation for why males vary in the number of females they dominate, it is complicated by the fact that, in this population, female resistance remains the primary predictor of male mating success (Freeman, 2012). It may be that there is a trade-off between female cooperation and resistance, possibly in relation to female matriline size. That is, if the latter is linked to female rank position and network connectedness, it may influence the extent to which males represent valuable allies for females in other domains. Clearly, despite the relative transience of male residency (Henzi \& Lucas, 1980) and the fact that females form the stable core of vervet groups, the fates of males and females are tied together in ways that require deeper consideration of how the social networks of adults intersect both within and between the sexes (Kudo \& Dunbar, 2001).

\section{Acknowledgments}

We are grateful to Mark and Sarah Tompkins for permission to work at Samara Private Game Reserve. We are indebted to all students and research assistants for help with data collection, and to Richard and Kitty Viljoen for ongoing logistical support. We thank Christof Neumann for statistical input and Julie Duboscq, Gisela Kopp and Oliver Schülke for helpful discussions. Advice and suggestions from Dr Alicia Melis and three anonymous referees greatly improved the manuscript. Our research was funded by National Research Foundation (South Africa) awards to S.P.H. and Natural 
Science and Engineering Council awards (Canada) awards to S.P.H. and L.B. The authors declare no competing interests.

\section{References}

Albers, P. C. H., \& de Vries, H. (2001). Elo-rating as a tool in the sequential estimation of dominance strengths. Animal Behaviour, 61, 489-495.

Altmann, J. (1974). Observational sampling of behavior: Sampling methods. Behaviour, 49, 227-266.

Andersson, M., \& Simmons, L. W. (2006). Sexual selection and mate choice. Trends in Ecology \& Evolution, 21, 296-302.

Archie, E. A., Tung, J., Clark, M., Altmann, J., \& Alberts, S. C. (2014). Social affiliation matters: Both same-sex and opposite-sex relationships predict survival in wild female baboons. Proceedings of the Royal Society B, 281, 20141261.

Barton, K., \& Barton, M. K. (2015). Package 'MuMIn'. ftp://155.232.191.229/cran/web/ packages/MuMIn/.

Bates, D., Maechler, M., Bolker, B., \& Walker, S. (2015). Fitting linear mixed-effects models using lme4. Journal of Statistical Software, 67, 1-48.

Berghänel, A., Ostner, J., \& Schülke, O. (2011). Coalitions destabilize dyadic dominance relationships in male Barbary macaques (Macaca sylvanus). Behaviour, $148,1256-1274$.

Burnham, K. P., Anderson, D. R., \& Huyvaert, K. P. (2011). AIC model selection and multimodel inference in behavioral ecology: Some background, observations, and comparisons. Behavioral Ecology and Sociobiology, 65, 23-35.

Castles, M., Heinsohn, R., Marshall, H. H., Lee, A. E. G., Cowlishaw, G., \& Carter, A. J. (2014). Social networks created with different techniques are not comparable Animal Behaviour, 96, 59-67.

Chase, I. D., Tovey, C., Spangler-Martin, D., \& Manfredonia, M. (2002). Individual differences versus social dynamics in the formation of animal dominance hierarchies. Proceedings of the National Academy of Sciences, 99, 5744-5749.

Colquhoun, D. (2014). An investigation of the false discovery rate and the misinterpretation of p-values. Royal Society Open Science, 1, 140216.

Creel, S., Dantzer, B., Goymann, W., \& Rubenstein, D. R. (2013). The ecology of stress: Effects of the social environment. Functional Ecology, 27, 66-80.

Csardi, G., \& Nepusz, T. (2006). The igraph software package for complex network research. InterJournal, Complex Systems, 1695, 1-9.

Franz, M., \& Alberts, S. C. (2015). Social network dynamics: The importance of distinguishing between heterogeneous and homogeneous changes. Behavioral Ecology and Sociobiology, 69, 2059-2069.

Freeman, N. J. (2012). Some aspects of male vervet monkey behaviour (MSc. Dissertation). Lethbridge, Canada: University of Lethbridge.

Freeman, N. J. Young, C. Barrett, L. \& Henzi, S. P. (2016). Coalition formation by male vervet monkeys (Chlorocebus pygerythrus) in South Africa. Ethology, 122, 45-52.

Gowaty, P. A. (2004). Sex roles, contests for the control of reproduction, and sexua selection. In P. M. Kappeler, \& C. P. van Schaik (Eds.), Sexual selection in primates: New and comparative perspectives (pp. 37-54). Cambridge, U.K.: Cambridge University Press.

Harrison, X. A. (2015). A comparison of observation-level random effect and betabinomial models for modelling overdispersion in binomial data in ecology \& evolution. PeerJ, 3, e1114.

Hemelrijk, C. K., Wantia, J., \& Isler, K. (2008). Female dominance over males in primates: Self-organisation and sexual dimorphism. PLoS One, 3, e2678.

Henzi, S. P. (1981). Causes of testis-adduction in vervet monkeys (Cercopithecus aethiops pygerythrus). Animal Behaviour, 29, 961-962.

Henzi, S. P. (1982). Some aspects of visual signaling and social organisation in the vervet monkey (Cercopithecus aethiops) (PhD Thesis). Durban, South Africa: University of Natal.

Henzi, S. P., \& Barrett, L. (2003). Evolutionary ecology, sexual conflict, and behavioral differentiation among baboon populations. Evolutionary Anthropology, 12, 217-230.

Henzi, S. P., Forshaw, N., Boner, R., Barrett, L., \& Lusseau, D. (2013). Scalar social dynamics in female vervet monkey cohorts. Philosophical Transactions of the Royal Society B, 368, 20120351.

Henzi, S. P., \& Lawes, M. (1987). Breeding season influxes and the behaviour of adult male samango monkeys (Cercopithecus mitis albogularis). Folia Primatologica, 48 , 125-136.

Henzi, S. P., \& Lucas, J. P. (1980). Observations on the inter-troop movement of adult vervet monkeys (Cercopithecus aethiops). Folia Primatologica, 33, 220-235.

Josephs, N., Bonnell, T., Dostie, M., Barrett, L., \& Henzi, S. P. (2016). Working the crowd: Sociable vervets benefit by reducing exposure to risk. Behavioral Ecology, 27, 988-994.
Keddy, A. C. (1986). Female mate choice in vervet monkeys (Cercopithecus aethiops sabaeus). American Journal of Primatology, 10, 125-134.

King, G., \& Roberts, M. E. (2015). How robust standard errors expose methodological problems they do not fix, and what to do about it. Political Analysis, 23, 159-179.

Kraus, C. C., Heistermann, M. M., \& Kappeler, P. M. P. M. (1999). Physiological suppression of sexual function of subordinate males: A subtle form of intrasexual competition among male sifakas (Propithecus verreauxi)? Physiology \& Behavior, 66, 855-861.

Kudo, H., \& Dunbar, R. (2001). Neocortex size and social network size in primates. Animal Behaviour, 62(4), 711-722.

Kummer, H. (1967). Tripartite relations in hamadryas baboons. In S. A. Altmann (Ed.), Social communication among primates (pp. 63-71). Chicago, IL: University of Chicago Press.

Leiva, D., \& De Vries, H. (2011). Steepness: testing steepness of dominance hierarchies. $R$ package version 0.2 . http://cran.r-project.org/web/packages/steepness/index. html.

McFarland, R., Fuller, A., Hetem, R. S., Mitchell, D., Maloney, S. K., Henzi, S. P., et al. (2015). Social integration confers thermal benefits in a gregarious primate. Journal of Animal Ecology, 84, 871-878.

Nakagawa, S., \& Schielzeth, H. (2012). A general and simple method for obtaining R2 from generalized linear mixed-effects models. Methods in Ecology and Evolution, 4, 133-142.

Neumann, C., Duboscq, J., Dubuc, C., Ginting, A., Irwan, A. M., Agil, M., et al. (2011). Assessing dominance hierarchies: Validation and advantages of progressive evaluation with Elo-rating. Animal Behaviour, 82, 911-921.

Neumann, C., \& Kulik, L. (2014). Animal dominance hierarchies by Elo rating. https:// cran.r-project.org/web/packages/EloRating/EloRating.pdf.

Nguyen, N., Horn, R. C., Alberts, S. C., \& Altmann, J. (2009). 'Friendships' between new mothers and adult males: Adaptive benefits and determinants in wild baboons (Papio cynocephalus). Behavioral Ecology and Sociobiology, 63, 1331-1344.

Ostner, J., Vigilant, L., Bhagavatula, J., Franz, M., \& Schülke, O. (2013). Stable heterosexual associations in a promiscuous primate. Animal Behaviour, 86, 623-631.

Pan, Y., \& Jackson, R. T. (2008). Ethnic difference in the relationship between acute inflammation and serum ferritin in US adult males. Epidemiology and Infection, 136, 421-431.

Papke, L. E., \& Wooldridge, J. (1993). Econometric methods for fractional response variables with an application to $401(\mathrm{k})$ plan participation rates. Cambridge, MA: National Bureau of Economic Research.

Pasternak, G. M., Brown, L. R., Kienzle, S., Fuller, A., Barrett, L., \& Henzi, S. P. (2013). Population ecology of vervet monkeys in a high latitude, semi-arid riparian woodland. Koedoe, 55, 1078.

Raleigh, M. J., \& McGuire, M. T. (1989). Female influences on male dominance acquisition in captive vervet monkeys, Cercopithecus aethiops sabaeus. Animal Behaviour, 38, 59-67.

Silk, J. B. (2002). Practice random acts of aggression and senseless acts of intimidation: The logic of status contests in social groups. Evolutionary Anthropology, $11,221-225$.

Soltis, J., Mitsunaga, F., Shimizu, K., Nozaki, M., Yanagihara, Y., Domingo-roura, X. et al. (1997). Sexual selection in Japanese macaques ii: Female mate choice and male-male competition. Animal Behaviour, 54, 737-746.

Struhsaker, T. T. (1967). Social structure among vervet monkeys (Cercopithecus aethiops), Behaviour, 29, 83-121.

Surbeck, M., \& Hohmann, G. (2013). Intersexual dominance relationships and the influence of leverage on the outcome of conflicts in wild bonobos (Pan paniscus). Behavioral Ecology and Sociobiology, 67, 1767-1780.

Surbeck, M., Mundry, R., \& Hohmann, G. (2011). Mothers matter! Maternal support, dominance status and mating success in male bonobos (Pan paniscus). Proceedings of the Royal Society B, 278, 590-598.

Wittig, R. M., Crockford, C., Seyfarth, R. M., \& Cheney, D. L. (2007). Vocal alliances in chacma baboons (Papio hamadryas ursinus). Behavioral Ecology and Sociobiology, 61(6), 899-909.

Wong, B. B. M., \& Candolin, U. (2005). How is female mate choice affected by male competition? Biological Reviews, 80, 559-571.

Young, C., Majolo, B., Schülke, O., \& Ostner, J. (2014). Male social bonds and rank predict supporter selection in cooperative aggression in wild Barbary macaques. Animal Behaviour, 95, 23-32. 